Spatial Demography 2014 2(1): 66-71

http://spatialdemography.org

OPEN ACCESS

via Creative Commons 3.0

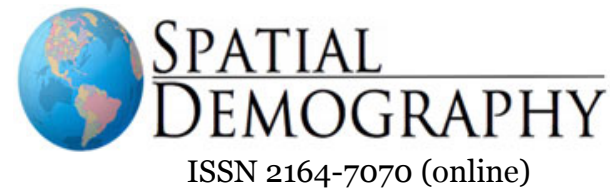

\title{
COLUMN
}

\section{Drawing Over-reaching Conclusions from Spatial Health Data}

\author{
Lee R. Mobley \\ Editor, Spatial Data
}

More and more often, published research using non-representative spatial data are used to draw over-reaching conclusions in health research. In this column, results from a recent literature review will reveal how prevalent this sort of 'bad science' has become. Also in this column, a specific example of over-reaching conclusions is demonstrated based on a widely cited and publicized article. Because the data used were not spatially representative of counties in the US, the authors used Bayesian small area estimation techniques to interpolate values for counties with no data. They over-reached when they concluded that the smoothed data on predicted diabetes rates in counties of the US provided actionable evidence for health policy makers to do targeted interventions, focusing on counties with worst predicted diabetes prevalence as a way to allocate scarce resources.

More specifically, the authors used small, surveybased samples from the Behavioral Risk Factor Surveillance System [BRFSS] and touted their approach as a new way to identify areas in greatest need of diabetes intervention. This study used predicted diabetes prevalence data (CDC, 2009) to identify 644 high-risk counties in a wide "diabetes belt" across the Southeast (Barker et al., 2011) (Exhibit 1). Based on the study's findings, the authors prescribed that investments in diabetes control interventions and infrastructure are urgently needed in more than $25 \%$ of U.S. counties. However, the methodology used in the study is inherently descriptive and masks the considerable spatial heterogeneity that exists among counties. Thus, it provides imprecise information regarding where there is greatest need. The mistake made by the authors was using a smoothing technique to enable generalizing their findings beyond the information available in the survey data.

Findings from surveys that are not spatially representative of the areal units they reveal are not generalizable beyond the survey sample respondents. BRFSS is spatially representative at the state level by design, and county codes are provided for respondents. But the county data are not spatially representative by sample design. However, a few states have augmented their data with additional surveys fielded from time to time to yield data that are more representative of their counties. Only two states that we know of (Florida and Illinois) have actually used countystratified samples to yield fully representative data at the county level.

The BRFSS sample on which the Barker et al. (2011) study was based was not designed to be a spatially representative sample of county populations; however, the county of residence is recorded for respondents. The sample sizes in many counties were too small to produce direct estimates of local outcomes, and some counties were not represented at all (Frazier et al., 1992). Using the same publicly available BRFSS data pooled over 2007 and 2008 that Barker et al (2011) used, along with the estimates for diabetes prevalence that were distributed online (CDC, 2009), we find $54 \%$ of counties $(1,692 / 3,117)$ having less than 50 observations. This number of respondents is the minimum required by $\mathrm{CDC}$ for 
reporting county prevalence as a direct estimate (Frazier et al., 1992). We find that for $26 \%$ of counties, there were no data collected for the survey over the 2 years.
In Exhibit 1, the diabetes belt graphic from Barker et al. (2011, Figure 2) has been reproduced using CDC's predicted diabetes prevalence data (CDC, 2009) merged with BRFSS survey data for

Exhibit 1. The Predicted Diabetes Belt, and Sample Sizes in Counties Used for the Prediction
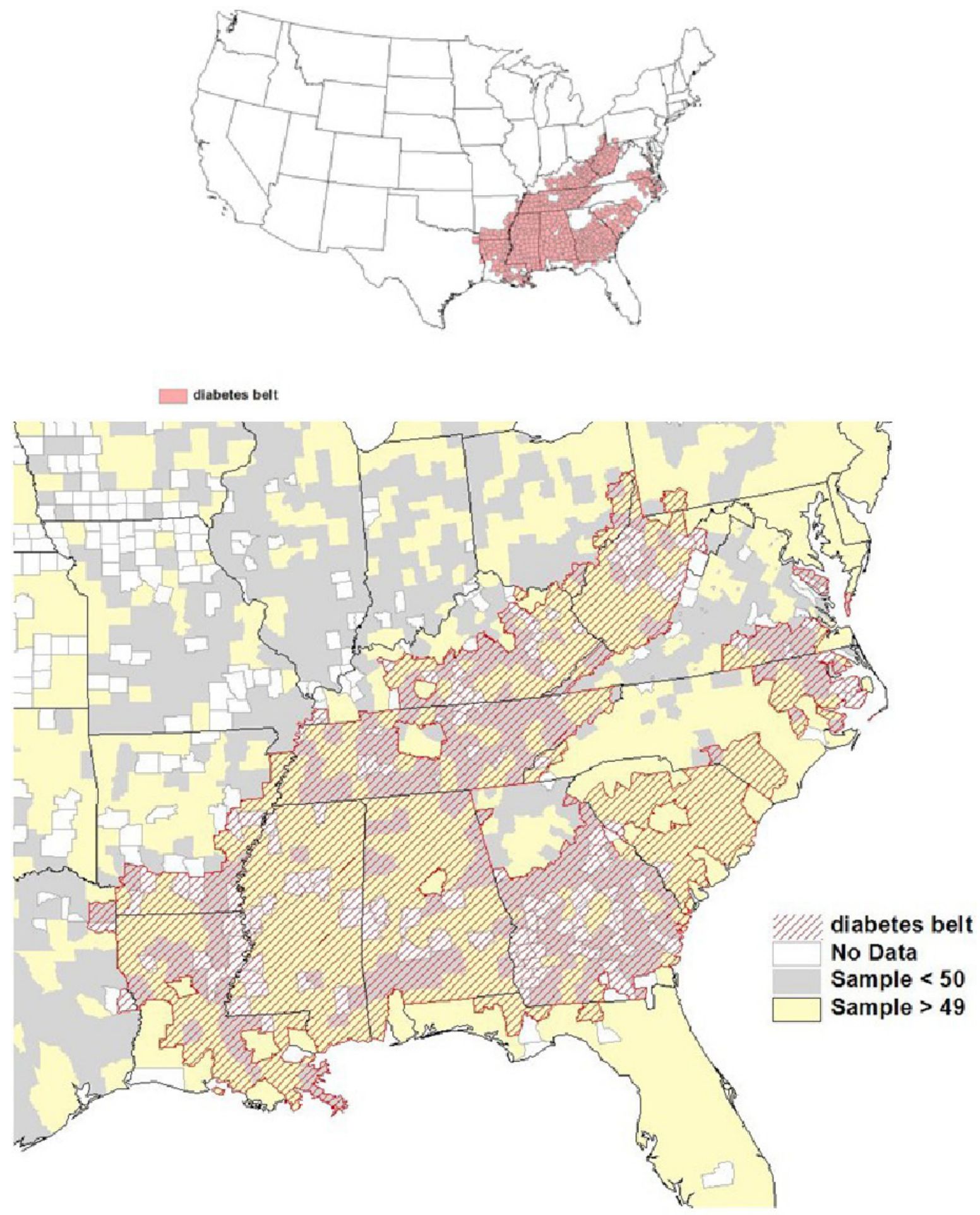
2007-2008 which provided the necessary information regarding sample sizes in counties. We show the $54 \%$ of counties in Barker et al.'s identified diabetes belt where the BRFSS included less than 50 sample observations, and the $26 \%$ of counties identified in the belt where the BRFSS included no data whatsoever. Areas with more than 50 sample observations are colored in gold. The diabetes belt is overlaid with a red crosshatched pattern. Focusing on the areas beneath the red crosshatched pattern, it is evident that the wide swath of the predicted belt across the state of Georgia was based on little actual sample information. The counties in the Atlanta metropolitan area, with large sample sizes, were not included in the belt. South Carolina data are more reliable, because the state systematically oversamples to yield at least 50 sample respondents in each county, so the existence of a diabetes belt there is more credible.

This paper by Barker et al provides one concrete example of mis-interpreting the results from spatially referenced health data to draw overreaching conclusions. I was curious regarding how prevalent this sort of practice is in the health sciences literature. To satisfy my curiosity, I performed a cursory literature search in PubMed for all studies published 2008 to present analyzing data in multivariate statistical models drawn from two national surveys: the National Health and Nutrition Examination Survey (NHANES), and the Behavioral Risk Factor Surveillance (BRFSS) survey. I chose these two surveys because they provide geographic identifiers for respondents that are at a lower level of geography than the survey design will support. That is, they are not spatially representative of populations at those lower levels of geography.

The purpose of the literature review is to determine what proportion of identified, relevant studies drew over-reaching conclusions based on the geographic identifiers available for the respondents. The literature search used the following search terms: survey names NHANES, BRFSS and the words county, census tract, geography, geographic, small area, multilevel, or contextual. The search was conducted for each survey and word paired individually (i.e. survey name "NHANES" and search word "county", survey name "NHANES" and search word "census tract", survey name "NHANES" and search word "geography", etc.). This PubMed search resulted in 58 unique peer-reviewed journal articles which I deemed to be relevant based on review of their abstracts. I excluded studies that were essentially methodological, or examined a single county, duplicated work published in several places, or blended data from 2 or more surveys.

Table 1 provides a summary of the 58 articles I used for this literature assessment, sorted by survey type. The use of the geographic identifiers in the NHANES survey in published health research is much less common than the use of the BRFSS geographic identifiers. This is because use of the NHANES geographic identifiers requires approved analytic plans for work conducted inside secure Research Data Centers. Of the 7 relevant NHANES articles, in my opinion only one made correct geospatial inferences for the NHANES sample in the abstract. Of the 44 relevant BRFSS studies, in my opinion only 7 made correct geospatial inferences for the BRFSS sample in the abstract. The dismal, overall success rate was 8 out of 50 articles which make correct inferences about geospatial data or geographic areas in their abstracts. Thus the over-reaching and over-generalized conclusions drawn from public health studies using geographic identifiers seems to be prolific. Scanning the list of journals associated with the studies in Table 1, one can see that this prevalence permeates a wide spectrum of public health journals, even reaching the top tiered ones.

Perhaps some of the problem is due to confusion 
Table 1. Results from Literature Search in PubMed

\begin{tabular}{|c|c|c|}
\hline Determination & Title and/or Journal & Details \\
\hline \multicolumn{3}{|l|}{ NHANES } \\
\hline $\begin{array}{l}\text { Correct } \\
\text { Interpretation }\end{array}$ & $\begin{array}{l}\text { "Linkage of the 1999-2008 National Health and } \\
\text { Nutrition Examination Surveys to traffic indicators from } \\
\text { the National Highway Planning Network", Natl Health } \\
\text { Stat Report }\end{array}$ & $\begin{array}{l}\text { Correctly interpret findings in the context of the sample } \\
\text { data, which was designed to represent states }\end{array}$ \\
\hline Over-generalization & Int J Public Health, Popul Health Metr, PLoS One & $\begin{array}{l}3 \text { studies compute or predict county-level prevalence } \\
\text { although the sample design is nationally representative, } \\
\text { not representative of counties }\end{array}$ \\
\hline Over-generalization & $\begin{array}{l}\text { Am J Epidemiol, Econ Hum Biol, Environ Health } \\
\text { Perspect }\end{array}$ & $\begin{array}{l}3 \text { studies investigate the association between area-level } \\
\text { contextual factors and outcomes based on survey sample } \\
\text { not designed to represent those areas }\end{array}$ \\
\hline \multicolumn{3}{|l|}{ BRFSS } \\
\hline $\begin{array}{l}\text { Correct } \\
\text { Interpretation }\end{array}$ & $\begin{array}{l}\text { "Geographic access and the use of screening } \\
\text { mammography", Med Care }\end{array}$ & $\begin{array}{l}\text { Results are reported in the context of the sample } \\
\text { population, and not generalized beyond them }\end{array}$ \\
\hline $\begin{array}{l}\text { Correct } \\
\text { Interpretation }\end{array}$ & $\begin{array}{l}\text { "Community attitudes about discussing sexual health: } \\
\text { assessing public opinion of local STD prevention } \\
\text { campaigns", Public Health Rep }\end{array}$ & $\begin{array}{l}\text { County-level predictors were included to assess } \\
\text { outcomes from a sample that was designed to be } \\
\text { representative of each county in the state of New York }\end{array}$ \\
\hline $\begin{array}{l}\text { Correct } \\
\text { Interpretation }\end{array}$ & $\begin{array}{l}\text { "Health disparities in clinical practice patterns for } \\
\text { prostate cancer screening by geographic regions in the } \\
\text { United States: a multilevel modeling analysis", Prostate } \\
\text { Cancer Prostatic Dis }\end{array}$ & $\begin{array}{l}\text { Analyzed geographic variability by state, based on a } \\
\text { sample that was designed to be representative of states }\end{array}$ \\
\hline $\begin{array}{l}\text { Correct } \\
\text { Interpretation }\end{array}$ & $\begin{array}{l}\text { "Recent trends and geographic patterns of the burden of } \\
\text { disease attributable to smoking", Value Health }\end{array}$ & $\begin{array}{l}\text { Analysis quantified the overall burden of smoking for the } \\
\text { nation and individual states, based on a sample that was } \\
\text { designed to be representative of states }\end{array}$ \\
\hline $\begin{array}{l}\text { Correct } \\
\text { Interpretation }\end{array}$ & $\begin{array}{l}\text { "Analysis of primary risk factors for oral cancer from } \\
\text { select US states with increasing rates", Tob Induc Dis }\end{array}$ & $\begin{array}{l}\text { Examined the risk factors for oral cancer among for the } \\
\text { individual states, based on a sample that was designed to } \\
\text { be representative of states }\end{array}$ \\
\hline $\begin{array}{l}\text { Correct } \\
\text { Interpretation }\end{array}$ & $\begin{array}{l}\text { "State ranks of incident cancer burden due to overweight } \\
\text { and obesity in the United States", Obesity }\end{array}$ & $\begin{array}{l}\text { Examined variability in state rankings, based on a } \\
\text { sample that was designed to be representative of states }\end{array}$ \\
\hline $\begin{array}{l}\text { Correct } \\
\text { Interpretation }\end{array}$ & $\begin{array}{l}\text { "Routine checkups don't ensure that seniors get } \\
\text { preventive services", J Fam Pract }\end{array}$ & $\begin{array}{l}\text { Analyzed predictors of outcomes by state, based on a } \\
\text { sample that was designed to be representative of states }\end{array}$ \\
\hline Over-generalization & $\begin{array}{l}\text { J Obes, Health Serv Res., Am J Health Promot, Health } \\
\text { Place, Prev Chronic Dis (2), , J Community Health, Am } \\
\text { J Prev Med, J Health Psychol, BMC Public Health }\end{array}$ & $\begin{array}{l}10 \text { studies that perform individual-level analysis with } \\
\text { area-level contextual variables, and fail to interpret } \\
\text { ecological effect findings as conditional on a sample not } \\
\text { representative of these areas }\end{array}$ \\
\hline Over-generalization & $\begin{array}{l}\text { MMWR Surveill Summ (5), Prev Chronic Dis., Appl } \\
\text { Geogr., J Public Health Manag Pract.(2), Community } \\
\text { Dent Oral Epidemiol, Am J Prev Med (2), Ophthalmic } \\
\text { Epidemiol, BMC Public Health, Disabil Health J, J } \\
\text { Public Health Manag, Prostate Cancer Prostatic Dis, } \\
\text { Am J Public Health, Health Place }\end{array}$ & $\begin{array}{l}19 \text { studies report prevalence or examine outcomes at } \\
\text { various spatial scales, based on samples not designed to } \\
\text { represent those spatial scales }\end{array}$ \\
\hline Over-generalization & $\begin{array}{l}\text { Int J Public Health, Rural Health, Cancer Med, Online J } \\
\text { Public Health Inform, BMC Health Serv Res, BMC } \\
\text { Public Health, J Asthma, Soc Sci Med }\end{array}$ & $\begin{array}{l}8 \text { studies contrast urban-rural findings based on samples } \\
\text { not designed to represent all urban and rural areas }\end{array}$ \\
\hline Over-generalization & $\begin{array}{l}\text { Womens Health Issues, Prev Chronic Dis (2), Rev } \\
\text { Panam Salud Publica, Am J Prev Med }\end{array}$ & $\begin{array}{l}5 \text { studies use small area models or small area estimation } \\
\text { methods to predict prevalence rates in counties, even } \\
\text { those with no sample data, based on a sample that was } \\
\text { not designed to be representative at the county level }\end{array}$ \\
\hline Mis-generalization & Public Health Rep, J Clin Sleep Med & $\begin{array}{l}2 \text { studies analyze disparities in state and metropolitan } \\
\text { areas based on survey sample designed to represent } \\
\text { states; however, survey is not designed to be } \\
\text { representative of metropolitan areas. }\end{array}$ \\
\hline
\end{tabular}


regarding what is spatially sufficient. I have written an earlier editorial specifically on this topic (Mobley, 2013). The Centers for Disease Control has published a protocol stating that less than 50 sample members is inadequate to generate a robust prevalence estimate (Frazier et al., 1992). They refer to larger samples that meet this minimum threshold as being 'geographically sufficient'. A very important distinction needs to be made regarding the difference between this meaning, and what is actually geographically (spatially) representative of the population. Spatially representative samples are designed to represent specific spatial areal units. BRFSS is designed to represent state-level populations. Having more than 50 county observations per county does not guarantee that the sample actually adequately represents the population in the county. Given that the BRFSS response rate is less than $50 \%$, and almost $2 / 3$ of US counties are not included in the survey at all, it is almost certain that it will not adequately represent the population in the county.

The counties included among the sampled respondents' residential locations in the BRFSS certainly are not representative of all counties in the US. A common mistake in the analyses using BRFSS data is to over-generalize county effect estimates as though they were representative of all areas of the US. Another common error is to assume that robust inferences can be made regarding urban-rural differences from the BRFSS sample. Another common error is to assume that the BRFSS is representative of metropolitan areas, which is promoted by the 'Smart BRFSS' data available online. These data were not derived from surveys designed to be representative of those metropolitan areas. They are simply aggregates of data over urban areas with dense sampling than meets the $>50$ per county criterion for public reporting of epidemiological rates (Frazier et al., 1992).
Another source of confusion is the survey design weights provided for survey analyses. For BRFSS, these survey design weights are correctly used to 'weight up' the sample respondents to represent the state population in terms of population demographics. They are NOT designed to 'weight up' the sample respondents to represent neighbors in their counties, or other spatial units and their use does NOT yield generalizable county-level predictions from the contextual data frequently used as covariates. For NHANES, which covers only a few dozen counties (exactly which ones remains a mystery, even to analysts inside the Research Data Centers), the survey design weights are correctly used to 'weight up' the sample respondents to represent the national population in terms of population demographics. Thus they are useless in 'weighting up' area-level contextual effects. Because people do not understand the weights or what they were designed to do, it is easy to assume that using them will make everything perfectly generalizable. This is not a correct assumption.

The important bottom line message I wish to impart in this editorial is that there are several ways to make mistakes in terms of overgeneralizing results from geo-referenced data. In preparing study abstracts, authors should be careful not to make sweeping conclusions regarding county contextual effects, urban-rural differences, or prevalence estimates generated for areas or locales that the data do not support. Before sending the article off for peer review, please ask yourself: what can I really glean from these results? Am I making the presumption that all places are equal, and that my handful are representative of everywhere? Are these results conditional on a small, non-representative sample at the geospatial level I am examining? One can always conclude correctly, as several authors have done, that the findings suggest (X, 
Y, Z) for the sample population (but caution should be used in generalizing the results beyond the sample population studied). This fact alone will explain many puzzling findings that seem inconsistent with other studies or have no apparent face validity. This is certainly a stronger concluding statement than "inconclusive/puzzling findings need further study”.

It is unfortunate in the US that truly spatially representative, population based health data are so scarce. Outside the cancer Registries, Medicare or Medicaid Fee-for- Service data, mortality statistics, and data collected by local health departments - data that represent all cases of a disease or people in entire subpopulations there are no population health data equivalent to what is available in other parts of the world. Thus, there are no counterfactual data available to refute the burgeoning studies that overgeneralize and draw over-reaching conclusions. In other developed nations, true population health census data exists and is invaluable for surveillance and predicting areas of greatest need. Let's push for less public health data privacy rather than pushing sparse data to misleading and ineffectual conclusions.

\section{References}

Barker, L. E., Kirtland, K. A., Gregg, E. W., Geiss, L. S., \& Thompson, T. J. (2011, April). Geographic distribution of diagnosed diabetes in the U.S.: A diabetes belt. American Journal of Preventive Medicine, 4O(4), 434-439. PubMed PMID: 21406277._

Centers for Disease Control and Prevention (CDC). (2009, November 20). Estimated county-level prevalence of diabetes and obesity, United States, 2007. Morbidity and Mortality Weekly Report, 58(45),1259-1263. Contains link to county-level prevalence estimates. Available February 2014 at: http://www.cdc.gov/mmwr/preview/mmwrhtml/mm 5845a2.htm.
Mobley, L., "What are Spatial Data? When are they Sufficient?” Spatial Demography, 2013 1(1): 120-130, available online: http://spatialdemography.org/wpcontent/uploads/2013/04/8.-Mobley.pdf. 